\title{
Representações de professores sobre o trabalho cotidiano com alunos com
}

\section{deficiencia}

\section{Representations of teachers about on work with students with disabilities}

\author{
Andreia Osti *, Susana Gakyia Caliatto **, Ana Paula Abdalla*** \\ * Universidade Estadual Paulista-UNESP ** Universidade do Vale do Sapucaí-UNIVAS *** EMEF. Cecy Ap. Rocha de Aguiar
}

\begin{abstract}
Resumen
O objetivo do estudo foi conhecer e analisar as representações de cinco professores acerca da inclusão de alunos com deficiência em uma escola pública, no interior de São Paulo, Brasil. O trabalho se fundamenta na Teoria das Representações Sociais que permite analisar as relações construídas na escola e suas repercussões na prática educativa. Para coleta utilizou-se uma entrevista e para o tratamento dos dados realizou-se a análise de conteúdo das respostas em virtude das temáticas que emergiram. Os resultados mostraram representações pautadas no senso comum indicando desafios de planejamento, atendimento ao deficiente, organização de atividades coletivas e formação para professores.

Palabras clave: Inclusão, Representação, Escola, Didática.
\end{abstract}

\begin{abstract}
The objective of the study was to know and analyze the representations of five teachers about the inclusion of students with disabilities in a public school, in the countryside of São Paulo, Brazil. The work is based on the Theory of Social Representations that allows analyzing the relationship built in the school and its repercussions in the educational practice. An interview was used for data collection and it was analyzed the content of the responses due to the themes that emerged. The results showed representations based on common sense indicating challenges of planning, attendance to the handicapped, organization of collective activities and training for teachers.

Keywords: Inclusion, Representation, School, Didactics.
\end{abstract}

\section{Introdução}

As representações sociais referem-se ao modo como as pessoas pensam e interpretam o cotidiano. De acordo com Moscovici (2013) todas as interações humanas implicam representações que alteram, sustentam e transformam a realidade. Desse modo, a Teoria das Representações Sociais pode fundamentar o estudo e a verificação de como as pessoas compreendem e disseminam ideias colocando-as em prática. Para Jodelet (2001) o homem busca explicar a realidade de diferentes maneiras e, com isso, cria representações. O fenômeno acontece como teorizações do senso comum, elaboradas coletivamente, nas interações. Para a autora trata-se de um saber prático da vida cotidiana que é compartilhado por meio dos diálogos e relacionamentos.
Assim, as representações desenvolvem e pertencem a um lugar na estrutura social, por estarem inseridas nos grupos sociais e culturais. São significados construídos a partir da vivência social, no pensamento das pessoas, transmitidos de geração em geração adquirindo um caráter natural e espontâneo (Jodelet, 2009).

Marková (2006) considera que "o conhecimento do senso comum está ao nosso redor e nós o adotamos, sejam para o melhor ou para o pior" (Marková, 2006. p. 196). É neste contexto que a Teoria das Representações Sociais pode ser eleita para subsidiar a pesquisa sobre representações e o conhecimento que delineiam a condição inclusiva na escola comum.

O processo de efetivação da educação inclusiva e a educação especial têm propiciado reflexões, debates e estudos diversificados no contexto educacional brasileiro, tendo em vista as deliberações nacionais mais recentes e específicas como o Plano Nacional de Educação em Direitos Humanos, 2006; Política Nacional de Educação Especial, 2008 e o Decreto $\mathrm{N}^{\circ}$ $6.571 / 2008$ sobre o atendimento educacional especializado - AEE na Educação Básica. Tais determinações nacionais resguardam as indicações dos principais acordos internacionais de promoção da inclusão: Declaração de Jomtien, 1990 - Declaração Mundial de Educação para Todos; Declaração de Salamanca de 1994 - Sobre Princípios, Políticas e Práticas na Área das Necessidades Educativas Especiais e a Convenção da Guatemala, 1999 da Eliminação de Todas as Formas de Discriminação contra as Pessoas Portadoras de Deficiência.

A educação inclusiva pode ser definida como uma ação política, cultural, social e pedagógica, suscitada em defesa do direito de todos os estudantes de estarem juntos para aprender e participar de todas as ações da escola, sem qualquer ato de discriminação, conforme princípios do Ministério da Educação - MEC (BRASIL, 2008). Segundo o mesmo documento, o movimento mundial pela inclusão, deflagrado a partir da década de 1990, enfatiza a necessidade de se alcançar uma educação de qualidade para todos, centrada no respeito e na valorização das diferenças.

Em consideração ao movimento inclusivo, ações afirmativas necessitam ser tomadas a fim de reparar perdas de direitos fundamentais e exclusão, historicamente, sofridas pelas pessoas com deficiência. 
Diante desse contexto, a literatura aponta que a educação inclusiva exige uma mudança de paradigma educacional e algumas medidas vêm sendo adotadas, tais como: a impossibilidade de negar vagas com base na deficiência do indivíduo, a extinção gradual da subdivisão de sistemas escolares de ensino especial e regular e a adoção do trabalho sem diferenciação de salas para alunos com e sem deficiência (Almeida \& Naiff, 2011; Mantoan, 2006).

Embora algumas providências inclusivas sejam adotadas, a mudança de paradigma não é uma realidade nas escolas brasileiras e, principalmente no que tange a aspectos metodológicos, está longe de ser um acontecimento. Isso pode ser evidenciado nas pesquisas levantadas para o presente artigo. Foram encontradas apenas três pesquisas em artigos na última década, que mostram do ponto de vista dos professores alguns aspectos inclusivos nas escolas no Brasil. Buscou-se principalmente aspectos da adoção (ou não) de posturas inclusivas por parte dos professores. As pesquisas apresentadas a seguir foram desenvolvidas no Ensino Fundamental de I ciclo em escolas públicas. A entrevista foi o instrumento para coleta de dados, sendo que Almeida e Naiff (2011) empregaram também, uma técnica de grupo focal. Para a discussão dos dados todas as pesquisas levantadas usaram técnicas inspiradas na análise de conteúdo.

Smeha e Ferreira (2008) exploraram o tema: prazer e o sofrimento docente diante dos processos de inclusão escolar. O objetivo foi identificar os sentimentos de prazer e sofrimento experimentados pelos professores que trabalham com a inclusão de alunos com necessidades educacionais especiais. Foram entrevistados quatro professores no sul do país. Os resultados apontaram que o sofrimento dos professores prevaleceu nas dificuldades em suas práticas. Atribuíram o sofrimento à falta de capacitação específica desde a formação acadêmica, além da carência de recursos disponibilizados pelas escolas para atender ao paradigma da educação inclusiva.

A pesquisa de Almeida e Naiff (2011) teve o objetivo de identificar as representações sociais existentes no contexto educacional com vistas à inclusão. O estudo foi desenvolvido com 120 professores e 100 alunos do Curso de Magistério que prepara futuros professores. As autoras constataram uma visão romanceada do processo de inclusão, embora o grupo apresentasse durante o desenvolvimento de grupos focais, a superação do medo e da insegurança para uma reflexão sobre acessibilidade. As autoras consideraram o resultado como o início da quebra de um antigo paradigma para construção de uma escola plural.

Por fim, a pesquisa de Briant e Oliver (2012) teve objetivo de conhecer estratégias pedagógicas, de 11 professores, para a inclusão de crianças com deficiência na classe comum. Os pesquisadores observaram que os entrevistados utilizavam estratégias gerais como aula expositiva, debates, e específicas como: avaliação dos alunos, adaptação do material, atividades em duplas, parceria com o professor da sala de apoio e acompanhamento à inclusão. Um outro dado observado se relaciona com a visão dos professores sobre a relação como os alunos com deficiência, que está permeada de possibilidades quando se acredita no potencial de aprendizagem dos mesmos. Contudo, há ainda o discurso de impossibilidade da aprendizagem de crianças com deficiência. Os docentes apóiam-se na necessidade de apoio institucional para seu trabalho, incluindo possibilidades de formação a partir das demandas cotidianas.

Nas pesquisas apresentadas verificou-se que as condições práticas e propostas de mudanças de atuação, além de uma possível mudança de postura em relação aos paradigmas escolares estiveram sempre em reflexão. Contudo, houve frequente cuidado para $o$ desenvolvimento de um discurso neutro de alguma forma de discriminação. Conclui-se que o debate superficial tem levado à execução de ações assistencialistas aos estudantes com deficiência, nas escolas e à recorrente consideração de que o professor está despreparado.

Apesar das constatações na literatura motivou-se ainda por perguntar: quais são as representações dos professores de uma mesma escola, de uma rede municipal, acerca da inclusão de alunos com deficiência nas classes de ensino comum, no estado de São Paulo, Brasil? No interior de uma escola pode existir uma realidade inclusiva específica em relação ao contexto brasileiro? Com o passar dos anos encontra-se uma tendência de modificação das representações encontradas pelo país? Propõe-se verificar e analisar as questões por meio da fundamentação teórica das Representações Sociais (Moscovici, 2010).

\section{Método}

\section{Participantes}

Os participantes foram cinco professoras que atuam em sala de aula comum com alunos com alguma deficiência. Todas com experiência em lecionar para esse público de alunos, sendo que quatro possuem mais de dez anos de experiência e uma mais de vinte. Apenas uma é pedagoga e outra estava cursando esta licenciatura em curso à distância. As quatro professoras não pedagogas são habilitadas em Magistério, um curso de nível secundário ou médio que preparava professores para o ensino de crianças, no Brasil. Sobre as formações específicas, duas professoras relataram serem psicopedagogas e uma especialista em educação especial. Na escola em que se desenvolveu a pesquisa, as professoras são auxiliadas por monitoras para atender as necessidades de alimentação e higiene de alunos com deficiência.

\section{Instrumento}

O instrumento ficou constituído de uma entrevista semi-estruturada com oito questões sobre a formação inicial do docente, a formação específica para o trabalho junto aos alunos com deficiência, as experiências com a inclusão escolar, os sentimentos e desafios de como está ocorrendo a inclusão em sala de aula. 


\section{Procedimento ético e de coleta de dados}

A pesquisa foi aprovada pelo Comitê de Ética da UNESP - Rio Claro, estado de São Paulo, sob o parecer $\mathrm{n}^{\circ}$ 1.012.750. Nos dias de entrevista iniciou-se a coleta recordando aos professores sobre os objetivos da pesquisa e foi pedido que assinassem o termo de consentimento livre e esclarecido (TCLE). A aplicação da entrevista foi gravada para promover um contexto semelhante ao de uma conversa informal. Os professores foram entrevistados individualmente, por aproximadamente 4 horas cada, ao logo de quatro dias. Não houve intercorrências durante as entrevistas.

\section{Procedimento de Análise dos Dados}

A análise dos dados foi inspirada pela Análise de Conteúdo de Bardin (2011). Assim, as gravações foram transcritas integralmente e efetuaram-se os passos de leitura flutuante, leitura minuciosa e a criação de categorias ou temas emergentes das falas das professoras. Os nomes dos professores foram substituídos por números e os nomes citados por eles foram substituídos por outros fictícios para preservar todas as identidades.

\section{Resultados e Discussão}

O objetivo do presente estudo foi conhecer e analisar as representações de cinco professores acerca da inclusão de alunos com deficiência em uma escola pública, no interior de São Paulo, no Brasil. Para atingilo consideramos que as representações sociais podem ser caracterizadas pela repetição de ideias que nos proporcionou a estruturação de temas. Os temas que emergiram foram quatro: Sentimentos relacionados à inclusão escolar; A formação do professor; Percepção do atendimento dado ao aluno com deficiência na sala de aula e Desafios da inclusão no cotidiano escolar.

Dos temas que emergiram apontamos duas categorias de representações dos professores. A primeira que diz respeito ao trabalho docente na escola inclusiva e aspectos pessoais em relação a ele. A segunda perspectiva de representação social é sobre a ideia que as professoras têm do alunado com deficiência.

As ideias formam representações que implicam nas práticas e ações educativas, pois, de acordo com Moscovici (1978): "Uma representação fala tanto quanto mostra, comunica, tanto quanto exprime. No final das contas, ela produz e determina comportamentos". Nesse sentido, as representações vão sendo cristalizadas e passadas, sendo tomadas como verdadeiras e muitas vezes repetidas sem a reflexão necessária.

$\mathrm{Na}$ presente pesquisa os relatos de dificuldades na atuação docente foram descritos por sentimentos de angústia, medo e solidão na atuação. De início, as professoras vinculam os sentimentos à falta de formação, seja a acadêmica como a formação continuada. Smeha e Ferreira (2008) concordam com nossa interpretação, pois concluíram que o sofrimento dos professores, diante do processo inclusivo, advém das dificuldades encontradas em suas práticas pedagógicas, pela falta de capacitação em sua formação acadêmica e carência de recursos para consentir ao paradigma da educação inclusiva.

Também Almeida e Naiff (2011) encontraram resultados análogos em suas pesquisas. As autoras observaram na fala de professores três elementos: o amor como resquício de um discurso antigo e assistencialista das associações para pessoas com deficiência, o respeito baseado no discurso politicamente correto ou num posicionamento de aceitação à inclusão e, a capacitação com base nas afirmativas de despreparo para lidar com as crianças com deficiência.

Para as professoras entrevistadas o exercício da docência, em atendimento às crianças com deficiência, necessita de modificações no sistema educacional, mas não sabem apontar como tais transformações poderiam acontecer. Apesar da falta de clareza das ideias, recuperamos Mantoan (2006) para corroborar com essa representação, afirmando que a inclusão implica em uma mudança de perspectiva educacional sendo que do ponto de vista inclusivo se suprime a subdivisão dos sistemas escolares em modalidades de ensino especial e regular, e se adotam novas condutas para que todos possam aprender no mesmo contexto escolar. E de acordo com Almeida e Naiff (2011), o objetivo principal da perspectiva inclusiva é viver a diversidade mesmo que seja um processo lento, isso porque nele está imbuído a tarefa de rever o conceito de homogeneidade que a escola implantou historicamente e que a sociedade vem perpetuando.

A presente pesquisa está alinhada a outros trabalhos de pesquisa (BRIANT; OLIVER, 2012; MANTOAN, 2001; SMEHA, FERREIRA, 2008) nos quais se apontaram fatores que dificultam a inclusão, como por exemplo, a falta de implantação das políticas previstas em lei, a ausência de materiais específicos para lidar com o aluno com deficiência, mas os chamou a atenção, sobretudo a falta de discussões sobre a inclusão dentro do espaço escolar. Houve indicações na fala das professoras, que na escola pesquisada faltam momentos de diálogo e reflexão sobre o atendimento ao aluno com deficiência. Isso reforçaria de certa forma, as representações de desamparo. Acreditamos que as trocas de experiência podem resultar em um melhor atendimento de todos os alunos, pois amplia conhecimentos do professor e possibilita o compartilhamento de materiais diversificados.

Tendo visto que o poder público municipal, no local da pesquisa, oferece o serviço de monitoria como auxílio ao aluno com deficiência em sala de aula comum, isso pode ser interpretado como um trabalho diferenciado, como possibilidade de trocas entre profissionais e como subsídio para minimizar os medos e receios das docentes no trabalho diário junto aos alunos com deficiência. Mas, nota-se que apesar desse diferencial, como um suporte (monitoras junto às professoras), ainda há na representação das professoras a inclusão com a falta de diálogo e falta da troca de experiências.

A respeito da espera pela mudança das estruturas educacionais, Stainback e Stainback (1999) sinalizam a necessidade de não se esperar que tudo seja concluído 
pelo poder público para então se programar ações de inclusão na sala de aula. Segundo os autores é necessário se pensar de forma processual quando esperamos mudanças atitudinais e comportamentais, e não somente estruturais e políticas.

As representações docentes, constituintes das respostas das professoras, em relação ao aluno com deficiência contemplaram conceitos de normal e anormal. Para Albuquerque (2007), comparar e descrever o que é normal e anormal, mesmo que considerando pessoas, é socialmente anterior ao movimento inclusivo. São representações pautadas em padrões de estética, beleza e modelos padronizados por isso, são representações trazidas da sociedade para o contexto escolar. Entendemos que representações de normalidade podem repercutir de forma negativa em ações de ensino e nos relacionamentos dos docentes com as crianças. Se partirmos de representações de normalidade, incidimos na homogeneidade das formas de aprender e na busca de adequar os alunos com deficiência ao sistema de ensino e adequar as atividades curriculares para cada aluno. Pensamentos e atitudes de adaptar, acomodar ou ajeitar não viabilizam ações inclusivas ou quando se acredita no respeito às diferenças (Mantoan, 2006).

Trabalhar considerando maneiras e ritmos diferentes de aprendizagem, parece-nos possível com novas propostas e maneiras originais de atuar na escola. Essas considerações são feitas a partir de Januzzi (2006) que suscita uma reestruturação do sistema comum de ensino e consequentemente das representações dos docentes, para que se focalize o ensino, a escola e as condições de aprendizagem, em detrimento do foco na deficiência. Para a autora, a escola inclusiva requer "uma mudança de concepção de ensino, pois, preza-se pelos recursos e apoios que a escola pode proporcionar ao aluno com deficiência ao invés de querer ajustar-lhe aos padrões de normalidade" (Jannuzzi, 2006, p. 188).

Encontramos diferentes percepções docentes sobre a aceitação do aluno com deficiência, sendo que duas professoras percebem que suas turmas aceitam positivamente os alunos com deficiência e as outras relatam o contrário. Outro ponto é que a deficiência física foi a mais citada como sendo um problema para o desenvolvimento do trabalho em prol da inclusão, ou pode-se dizer que a deficiência física foi representada como desafio para atuação das professoras.

Talvez um dos maiores entraves no processo de construção da escola inclusiva é o enfrentado na relação professor - aluno, pois pareceu-nos que os relacionamentos provocam ambiguidade de sentimentos e pensamentos. Na presente pesquisa, hora os relatos denotam posicionamentos e sentimentos negativos e hora positivos. As professoras afirmaram que o processo de inclusão é importante e necessário, contudo mencionam que na prática, a teoria não se confirma, referindo-se que os ideais inclusivos são dignos, mas impossíveis de serem propagados.

Interpreta-se que para as cinco professoras, a inclusão é representada como sendo necessária, importante, positiva aos alunos com deficiência, mas é um trabalho de muitas dificuldades. Os entrevistados mostram sentimentos de frustração com seu trabalho, mas em outras colocações relatam que se sentem preparadas para lidar com os alunos deficientes, no que se refere ao esmero (carinho, paciência, atenção, compaixão) dispensado aos mesmos alunos. Segundo Smeha e Ferreira (2008) evidenciou-se na pesquisa das autoras que, apesar de o sofrimento ser iminente, o prazer do professor em trabalhar com a inclusão está relacionado ao vínculo afetivo que ele estabelece com seus alunos, o que constitui uma representação positiva na prática docente.

Percebemos que alunos com deficiência despertam emoções e aparentemente os professores relacionam estes sentimentos com o comprometimento para compensar as dificuldades enfrentadas. Muitas vezes, com base nas emoções é que justificam seu trabalho inclusivo como sendo um desafio positivo. Briant e Oliver (2012) provocam uma reflexão das emoções em prol do avanço da inclusão em termos da prática em sala de aula considerando que as turmas que incluem crianças com deficiências podem ser tidas como um estímulo provocativo à adoção de novas estratégias por parte dos educadores. O que tornaria a sala de aula um ambiente mais rico de experiências inovadoras porque implica em proporcionar a participação do estudante com deficiência em todas as atividades realizadas e oportunizar a confecção de materiais mais interessantes.

Considera-se apesar dos avanços em pesquisas que afirmem a qualidade da inclusão para todos que dela participam, ainda temos um longo caminho a percorrer a fim de atender as diferentes necessidades dentro do mesmo ambiente escolar. Percebe-se que apesar da inclusão ter sido inserida no contexto educacional, ainda é necessário efetivar uma mudança em que a escola reveja sua estrutura, e os educadores e demais funcionários analisem suas práticas para atender a nova realidade apresentada: a inclusão de fato. Claro que desta mudança fazem parte as políticas públicas e as formações universitárias nos cursos de licenciatura.

A inclusão nos remete a ideia de sujeitos excluídos, e enquanto cidadãos não podemos ficar alheios ou fecharmos os olhos para esta realidade que está cada vez mais presente nas escolas e em nossa sociedade. Buscamos com este trabalho estimular a reflexão sobre o tema e contribuir para a efetivação de uma inclusão de qualidade para todos, principalmente em razão das dificuldades enfrentadas pelos professores frente a esse processo.

\section{Referencias}

Almeida, S. A de \& Naiff, L. A. M. (2011). Inclusão Educacional nas Representações Sociais de Professores e Estudantes de Magistério. Pesquisas e Práticas Psicossociais 6(1), São João Del-Rei. http://www.ufsj.edu.br/portal2-

repositorio/File/revistalapip/volume6_n1/Almeida_\%26 _Naiff.pdf

Brasil. (2008). Ministério da Educação. Secretaria de Educação Especial. Política nacional de educação especial na perspectiva da educação inclusiva. Brasília. http://portal.mec.gov.br/seesp/arquivos/pdf/politica.pdf 
Brasil. Declaração Mundial sobre Educação para Todos: plano de ação para satisfazer as necessidades básicas de aprendizagem. UNESCO, Jomtiem/Tailândia, 1990.

Brasil. Declaração de Salamanca e linha de ação sobre necessidades educativas especiais. Brasília: UNESCO, 1994.

Briant, M. E. P; Oliver, F. C. (2012). Inclusão de crianças com deficiência na escola regular numa região do município de São Paulo: conhecendo estratégias e ações. Rev. Bras. Ed. Esp., Marília, n.1, 141-154. http://www.scielo.br/pdf/rbee/v18n1/a10v18n1.pdf

Jannuzzi, G. S. de M. (2006). A educação do deficiente no Brasil: dos primórdios ao inicio do século XXI. $2^{a}$ edição. SP: Campinas, Autores Associados.

Jodelet, D. (2001). Representações sociais: um domínio em expansão. In: JODELET, D. (org.). As Representações sociais. Rio de Janeiro: Eduerj,17-44.

JODELET, D. (2009). O movimento de retorno ao sujeito e a abordagem das representações sociais. Sociedade e Estado, Brasília, v. 24, n. 3, 679-712.

Mantoan, M. T. E. (2001). Todas as crianças são bemvindas à escola. Revista Profissão Docente, v.1, n.2, 1 19.

http://www.revistas.uniube.br/index.php/rpd/article/vie w/32/515

Mantoan, M. T. E. (2006). Inclusão Escolar: O que é? Por quê? Como fazer? São Paulo: Moderna.

MARKOVÁ, I. (2006). Representações sociais: velhas e novas. In: Dialogicidade e representações sociais: as dinâmicas da mente. Petrópolis, RJ: Vozes.

MOSCOVICI, S. (1978, 2010). Representações sociais: investigações em psicologia social. Petrópolis, RJ: Vozes. 10. Ed.

SMEHA, L. N; FERREIRA, I de V. (2008). Prazer e sofrimento docente nos processos de inclusão escolar. Revista "Educação Especial" n. 31, 37-48, https://periodicos.ufsm.br/educacaoespecial/article/view 18 